\title{
Strength- and recovery-based approaches in forensic mental health in late modernity: Increasingly incorporating a human rights angle?
}

\author{
Jack Tomlin ${ }^{1} \cdot$ Melanie Jordan ${ }^{2}$
}

Accepted: 28 June 2021 / Published online: 13 July 2021

(C) The Author(s) 2021

\begin{abstract}
Forensic mental health care is situated across both criminal justice and healthcare systems and is subject to political, cultural, legal and economic shifts in these contexts. The implementation of strength- and recovery-based models of care should be understood in light of these social and structural processes. Drawing on novel empirical fieldwork and the extant literature, we argue that full realisation of strength- and recovery-based principles is at odds with aspects of late modern social control. Not wholly compatible, we highlight how concepts of empowerment, autonomy, identity and connectedness can unhelpfully rub-up against the concepts of punitiveness, otherness and risk management. Conceptually this is problematic, but in frontline forensic psychiatry settings, this has real lived-experience detrimental effects for patients - as our data demonstrate. To address this, a human rights approach might be fruitful. Grounding arguments for strength- and recovery-based principles in the heuristic framework of human rights can offer a set of common values to stimulate reform in forensic mental healthcare. The right to respect for private and family life, home and correspondence under Article 8 of the European Convention on Human Rights and Fundamental Freedoms offers a particularly promising, robust and welldefined framework for these future changes - as we outline.
\end{abstract}

Keywords Late modernity · Forensic mental health · Mentally disordered offender · Recovery $\cdot$ Human rights

Jack Tomlin

Jack.tomlin@med.uni-rostock.de

Melanie Jordan

Melanie.jordan@nottingham.ac.uk

1 Department for Forensic Psychiatry, Rostock University Medical Center, Gehlsheimer Straße 20, 18147 Rostock, Germany

2 School of Sociology and Social Policy, University of Nottingham, Room B24 Law and Social Sciences, University Park, Nottingham NG7 2RD, UK 


\section{Introduction}

\section{Social control and late modernity: A brief summary}

A series of developments in Western liberal democracies over the preceding half century (i.e. since the 1970s) including the growing politicisation of crime embodied in the punitive turn (Garland and Sparks 2000; Feeley and Simon 1992; Goshe 2017) and increased social emphasis on risk and the management of risky individuals (Rose 1998, 2000; Beck 1992) shape the contemporary provision of forensic mental health services.

The term 'late modernity' captures these broad social, political and economic shifts. Garland (2001) proposed that these have influenced the development of two ways in which social control agencies have sought to define and control risk and people considered 'risky'. The first of these is what is described variously as the 'Punitive Turn', 'Punitive Shift', 'Populist Punitivism', or 'Criminologies of the Other'. These refer to the resurgence of pre-modern sentiments on crime and criminals (Hallsworth 2000). Penal policies are typically characterised by expressive punishments, simple conceptions of crime causation, the condemnation and exclusion of wrongdoers, depictions of deviants as incorrigible others and attempts at symbolically and materially demonstrating the sovereign power of nation states over a weakened ability to ensure security within its jurisdiction (Garland and Sparks 2000; Garland 2001; Feeley and Simon 1992; Simon 1998; Reiner 2012).

A 'fear of the other' is manipulated in political discourse to explain and proffer solutions to citizens' ontological insecurity and perceived rising crime rates (Hollway and Jefferson 1997). Penal welfarism, programmes of socio-economic intervention, individual rehabilitation and treatment are drawn on less frequently than expressive punishment and retribution (Goshe 2017). Illustrative of this are trends in incarceration in England \& Wales. The total number of individuals incarcerated rose from $\sim 45,000$ in 1990 to 82,440 in 2019, the average sentence length has increased from 12.4 to 17.3 months between 2006 to 2018 , and the average minimum term imposed for murder cases ordered by judges rose from 12.5 to 21.3 years between 2003 and 2016 (Prison Reform Trust 2019). These trends occured despite an overall decrease in crime rates between 1995 and 2017, with a slight increase between 2017 and 2019 (Office for National Statistics 2019).

The second way in which social control agencies have sought to define and control risk and perceived risky people is acutely 'modern' in its ambitions (Hallsworth 2000). Described variously as the 'New Penology', 'Managerialism', 'Contrology', or 'Criminologies of the Everyday', these approaches refer to a widening of the 'social control net', a dispersal of responsibility for protecting oneself from perceived risks in day-to-day life, and the various actuarial measures and procedures underpinning these (Garland 2001; Garland and Sparks 2000; Feeley and Simon 1992; Simon 1998). Myriad social, political and economic phenomena characteristic of late modernity have in some scholars' eyes have left 
the state emaciated, its total grip on social control diluted (Garland 2001; for a critique of this perspective, see: Koch 2017).

The prediction of social deviance is, from this highly-critiqued perspective, a statistical endeavour in which those identified as risky may be restricted social intercourse or suffer complete social isolation (Bauman 2000). Some commentators see these efforts as inimical to a longer process of modernity in which risk and uncertainty are tamed through a process of knowledge accumulation, formal rationality and efficiency (Bauman 2000; Feeley and Simon 1992; Hallsworth 2000; Rose 2000).

Examples of this include the use of preventive detention for sexual offenders (Simon, 1998), Anti-Social Behavioural Disorders that exclude individuals from certain geographical spaces (Lewis et al. 2016), GPS monitoring of forensic patients on leave (Murphy et al. 2017) and the (now defunct) Dangerous and Severe Personality Disorder programme (Rutherford 2006). Risk is embedded in everyday life; it is not a discrete phenomenon acknowledged at interval, rather an omnipresence woven into social relations, institutional structures and physical spaces.

In summary, social control in late modernity is characterised by, amongst other things, punitiveness, otherness and the assessment and management of risk. In the present paper we explore the extent to which these broader social developments shape and interact with the discipline of forensic mental health care.

\section{Forensic mental health care}

Forensic mental health is tasked with the treatment of individuals with a mental disorder who pose a risk of harm to themselves and/or others. The majority of these individuals are labelled Mentally Disordered Offenders (MDOs). Having been found guilty of committing an offence in court, MDOs might receive a Hospital Order sending them to a secure forensic hospital instead of a penal setting. ${ }^{1}$ In England and Wales for example, a criterion for this is that at the time of sentencing the individual's '... suffering is of a nature or degree which makes it appropriate for him to be detained in a hospital for medical treatment' (s.37 Mental Health Act 1983 (as amended); MHA). MDOs can also be transferred to forensic settings from prison where their risk of harm to self or others is deemed to warrant security and care not available in penal settings. Secure hospitals function at low, medium and high security levels. Residence within a forensic hospital in England and Wales can be for an indefinite amount of time where 'appropriate medical treatment is available' (s.2(a) (i) MHA, 1983).

The rationale for dedicated forensic settings is that MDOs would benefit from a therapeutic environment in which to receive necessary mental health care, reduce risk and address criminogenic need. However, these can be highly restrictive, coercive and risk-averse settings (Tomlin et al. 2018; Horberg et al. 2012;

\footnotetext{
${ }^{1}$ In the U.K, the provisions for ordering a Hospital Order are found in the Mental Health Act 1983 (as amended).
} 
Markham 2018). Residents may be proscribed leave, have telephone calls and mail monitored, be denied intimate relationships, spend significant periods of time in seclusion, or have limits on the number of goods they store in their rooms, amongst other things (Tomlin et al. 2020). Patients' pathways through secure care reflect a mixture of social, political, cultural and clinical considerations (see Middleton and Jordan (2017) for a social scientific examination of mental healthcare services' relational elements: policy context, frontline normative work, staff knowledge, service users' desires, diagnosis experiences, etc.).

Forensic work includes complexity, role conflict and overlaps. For example, the legislature-healthcare boundary. Rees (2015) highlights how post-rape medical practitioners 'find themselves in the peculiar position of being required to meet the normative standards of both medicine and the law' (p. 141) - acting as a patient's clinician whilst examining a body and collecting any available evidence from a complainant for the courts. Forensic practitioners must negotiate their medicolegal spaces (Rees 2015), and working in this field requires both critical evidence consideration and therapeutic labour - in tandem (Rees 2015).

The justice-health relationship is apparent in yet further ways. After receiving treatment in a secure hospital, patients transferred from prison can be returned to prison under the UK Mental Health Act 1983. Some patients might have received significant media attention for their offences (Morley and Taylor 2016). This notoriety can have consequences for their successful progression through forensic services and back into the community. The possibility of a transfer back to prison or political pressure resulting from media coverage obfuscate individuals' progression through care due to considerations outside purely clinical concerns. Indefinite lengths of stay, media attention, legal controls directed by the Ministry of Justice crystalize into significant curtailments of a patient's liberty.

This curtailment is typically justified on the grounds of risk management (Markham 2018). Patients are mapped into low, medium and high security hospitals due to their assessed riskiness, thus providing the rationale for the structure of the secure system and directing the placement of patients (Kennedy 2002). The concept and performance of risk is arguably problematic across the criminal justice system, including courts, prisons, probation, police, youth custody service and the secure estate. Forensic mental health in this sense can be seen as one form of social control, managing dangerous individuals in a stratified care system (Feeley and Simon 1992; Rose 1998). Risk management is therefore pervasive across the services within which MDOs reside. These controls pose challenges to providing forensic mental health care, especially contemporary approaches that adopt strength- and recoverybased paradigms (Barnao and Ward 2015).

\section{Strength- and recovery-based approaches in forensic mental health care}

Contemporary models of mental health and offender rehabilitation embrace individual autonomy, empowerment and self-determination, seeing these as crucial to achieving positive outcomes. Two approaches in this vein being adopted in forensic 
settings are the Good Lives Model of Offender Rehabilitation (Ward and Brown 2004) and the Recovery Paradigm (Simpson and Penney 2011, 2018).

The Good Lives Model of Offender Rehabilitation (GLM) is a conceptual model with early empirical support that has been applied in both forensic and penal settings (Barnao et al. 2016; Bouman et al. 2009; Ward and Brown 2004). The GLM proposes that rehabilitative interventions should not focus solely on risk reduction strategies but should also aim to promote an individual's abilities, strengths, personal interests and opportunities to live a good life. This good life is characterised by the fulfilment of fundamental human goods, the attainment of which has been positively associated with well-being (Ward \& Brown, 2004).

Recovery is a process of living with and through mental disorder. Recovery is typically defined as an inherently subjective experience (Leamy et al. 2011). It may be considered a journey or an end point. Anthony (1993) defines recovery as ' $[. .]$. deeply personal, unique process of changing one's attitudes, values, feelings, goals, skills and/or roles [...] and a way of living a satisfying, hopeful and contributing life even with the limitations caused by illness' (p. 527).

Empowerment features in multiple accounts of recovery (Leamy et al. 2011). Conceptualizations emphasise that individuals should play a role in authoring their care plans, plan daily activities and take responsibility for their actions. This empowerment is contingent on a notion of autonomy and the ability to act as an independent agent (Jacobson and Greenley 2001). In doing so, individuals utilise knowledge and self-confidence when given the opportunity to make meaningful choices in life. The recovery paradigm therefore presupposes that individuals with mental disorders ought to take responsibility for, and through empowerment, self-determine their actions (Leamy et al. 2011). This paper discusses the intersection between these values and the broader social control aspects described earlier in the introduction. Literature and empirical data collected for this study are presented.

\section{Aims and structure of this paper}

The preceding raises questions as to what extent the approaches to social control indicative of late modernity as identified by Garland (2001) are visible in contemporary forensic mental health care and how these interact with or shape the implementation of strength- and recovery-based approaches to care. We argue that three characteristics of late modern social control - punitiveness, otherness and the assessment and management of risk - are all visible and routine. We build on past literature describing these tensions but add new empirical contributions to this debate. We include excerpts from and analysis of qualitative interviews $(N=18)$ undertaken in forensic psychiatric hospitals in England. We suggest that although aspects of late modern social control do impede the implementation of strength- and recoverybased approaches, appeals to human rights can serve as a core value around which stakeholders and advocates can navigate this impediment. For example, the right to respect for private and family life, home and correspondence under Article 8 of the European Convention on Human Rights and Fundamental Freedoms (ECHR 1953) offers a particularly promising, robust and well-defined framework to underpin 
future changes within forensic mental health care. It protects, amongst other things, individuals' 'physical, psychological or moral integrity', 'privacy' and 'identity and autonomy’ (Council of Europe 2019).

\section{Methodology and methods}

\section{Setting and recruitment}

The paper draws on extant literature and qualitative data collected for a project investigating forensic psychiatric patients' experiences of restrictiveness in secure hospitals (Tomlin et al. 2020). Participants were recruited from adult low, medium and high security hospitals in England between October 2017 and January 2018. These hospitals provide care for patients sectioned under the Mental Health Act 1983. These patients have most commonly been ordered into treatment following conviction for a criminal offence either directly from court or following a transfer from prison. Residents can also be detained under a civil section. All patients are deemed to pose a risk of harm to themselves or others.

Sampling was convenient but with purposive stratification (Lynn 2016). Wards and hospitals were approached so as to involve individuals receiving care: across all levels of security; in men's and women's settings; across admission, treatment and rehabilitation phases of the care pathway; and within different services compartmentalised into different diagnostic groups. Exclusion criteria included: the inability to speak English, a primary diagnosis of learning disability or the absence of the capacity to give informed consent.

Participants were recruited in the following way: the aims and methods of the project were presented to patients and staff during ward community meetings. Interested patients were given information sheets and agreed a time to meet for the interview. Capacity to give informed consent was assessed by the researcher in conjunction with members of the patients' care teams. Ethical approval for this study was given by the Leicestershire South Research Ethics Committee (REC:17/EM/0159), the University of Nottingham and the NHS Health Research Authority.

\section{Methods}

Given the encompassing nature of forensic settings, biographical, interactional, institutional and systemic features of care are produced and reproduced by defined groups of actors within them. In light of this, data collection and analysis were conducted cognisant of the socially constructed nature of participant experience (Kvale 2008). Each participant's experience was constructed as a unique narrative but seen as a lens through which broader socially constructed knowledge claims could be derived.

Focus groups were initially conducted but following poor attendance at the first two $(\mathrm{N}=3$ and $\mathrm{N}=2)$ the remaining participants were interviewed individually. 
Interviews were semi-structured (Silverman 2015). This allowed generalizable themes to emerge but gave respondents space to express themselves. Themes discussed included individual autonomy; diagnostic labelling and stigma; relationships with staff, patients and others outside the hospital; medication; the built environment; meaningful activities; and the law.

\section{Data analysis}

Interviews were audio-recorded, transcribed verbatim and analysed thematically. Thematic Network Analysis (TNA) was used (Attride-Stirling 2001). TNA offers a framework for deriving different levels of themes: basic, organising and global. Themes were generated using NVivo version 14 software. Full coding is described in Tomlin et al. (2020). Relevant extracts from these interviews are presented in this paper.

\section{Results}

Eighteen patients participated in the qualitative interviews. Full demographic, clinical and legal characteristics of participants are provided in Table 1.

\section{Punitiveness}

Secure hospitals aim to balance caring and custodial roles. However, the literature identifies a carcerality that seeps into the provision of care. Warburton (2016) describes secure hospitals as dangerous, punitive and controlling. This carcerality is captured visibly by the physicality of secure spaces. The literature highlights a tension between therapeutic ideals amidst locked doors, barbed wire fencing and alarms (Holmes and Murray 2011; Parrott 2005). The design of secure settings is influential, and attempts 'to introduce trauma-sensitive services in establishments that are replete with hostile architecture, overt security paraphernalia, and dilapidated fixtures and fittings is futile' (Jewkes et al., 2019: 3818).

Further, the custodial nature of the secure setting can be in part enforced by punitive staff and public attitudes. Staff can harbour attitudes that subsume therapeutic ideals. For instance, Ruane and Hayter (2008) report a member of staff stating of patients that "[t]hey should be having a miserable time. That's not a therapeutic attitude I know, and it doesn't really work very well but I do feel it from time to time" (p. 1737). Prohibitions on patients' sexual intimacy have been attributed to punitive attitudes despite there being little evidence to suggest such activity is harmful to patients (Quinn and Happell 2016).

Participants in the qualitive interviews described aspects of their care they felt were punitive: the use of handcuffs when on trips to the dentist, lengths of stay 


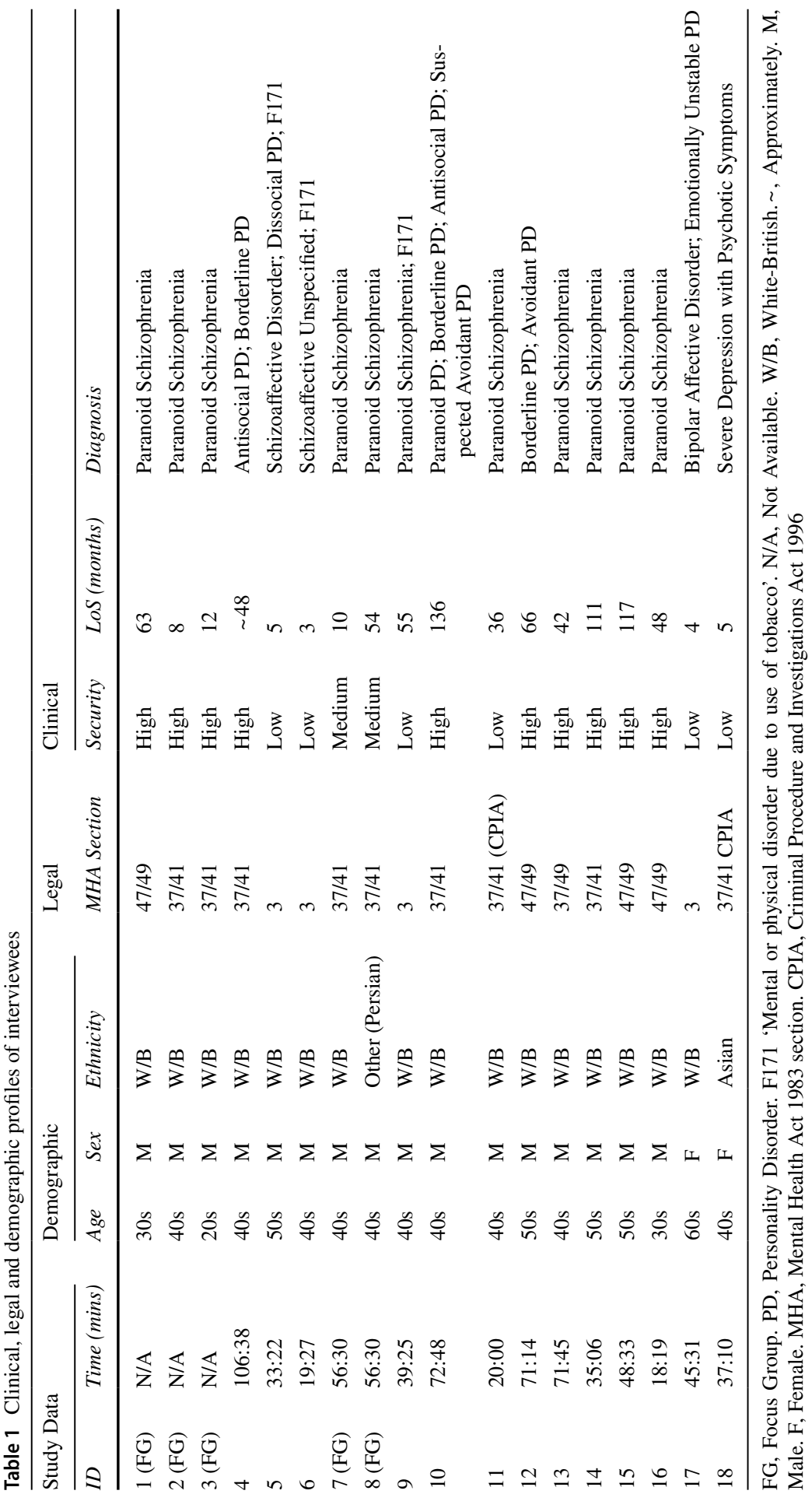


that exceeded their prison tariff, indefinite lengths of stay and the overall constraints of the setting. When asked if his hospital feels punitive, one participant remarked:

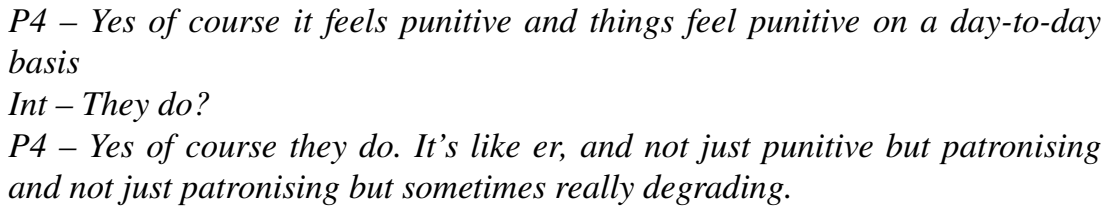

Punitiveness was not experienced by all participants. However, punishment and carcerality is evident in the interview data and literature. Punitiveness was experienced through the enacting of specific measures, on a day-to-day basis, and was sometimes attributed to public and staff attitudes shaping the provision of care. This blurred the boundaries between care and custody.

The existence of punitivism in what are ostensibly therapeutic environments might be contributable to what Goshe (2017) describes as the "philosophy of necessity'. The philosophy of necessity proposes that “... punishment is a necessary, if not always sufficient, response to crime and social problems” (p. 27). It sees punishment as the starting point, the dominant and organising principle of how society thinks about and responds to real and perceived harms. It serves a functional role. In a society, such as the U.S. and also to a lesser extent the U.K., with a thin welfare net and strong neo-liberal and meritocratic commitments, punishment is the way society admonishes individuals for failing to succeed within normative boundaries and have made the wrong choices - it justifies punishment.

\section{Otherness}

Mentally disordered offenders form an 'othered' social group (Rose 1998). This is in part due to a double stigma relating to their identity as both mentally unwell and the author of a criminal act (Mezey et al. 2016). Mezey et al. (2010) reported that patients felt that this stigma would negatively affect their recovery journey. Mezey et al. (2016) found that both forensic and general psychiatric patients report widespread experiences of stigma, particularly in relation to members of their close social circle. This is problematic as family and friends are a key resource when providing support after discharge. The consequences of this stigma is likely to follow MDOs through care into the community, impacting on occupational, housing and social opportunities (Corrigan and Watson 2006; Crisp et al. 2000).

Within the interviews, one participant residing in a high security hospital described it accordingly:

Pl - But yea, being here it's sort of, you know it's gonna stay with me for the rest of my life, you know erm, like I say there's only three of these hospitals in the country in't there? 
Participants narrated exclusion, whereby a single index offence might be the only thing other people 'see', and talk about, when interacting with them - that the stigma of the index offence is so great it overshadows everything else about that person. A past offence dominating current identity work and plans for the future. The secure hospital stay would continue to be a part of their future, even after discharge. It also continues to set them apart from the seemingly law-abiding persons - perpetually othering.

This stigma was anticipated to carry through until release into the community and restrict opportunities to find work, get insurance and establish new social bonds. Another respondent described the multidimensional quality of this stigma and how it would affect their reintegration into the community-in explaining this frustration, one resident remarked:

P4 - Actually I'm not gonna, you don't have to lock up all your fucking daughters, actually I'm not a rapist, actually I'm not gonna go out and take drugs, and damage the fucking area that I'm in, and become a one man crime wave ... There's a lot, I carry a lot of stigma with me.

Bauman (2000) proposed that the exclusion of certain groups performs a social function. He writes that social groups “... promote the 'proper' by sharpening the sights on the improper; they single out, circumscribe and stigmatize parts of reality denied the right to exist - destined for isolation, exile or extinction" (p. 25). Individuals that break social norms disrupt social order. By deviating from these norms, individuals become isolated from others that adhere. In this academic sense, they somewhat self-ostracise; these unilateral acts justify efforts by norm-adherents to remove the norm-breakers. When understood in this way, forensic patients are being removed from the norm-following social group. Critical here are the powerful social actors that define social norms; MDOs are unlikely to wield such influential social power to redefine normative values to be more inclusive.

\section{Risk}

Risk management is grounded in genuine concerns to prevent harmful behaviours that are heightened in secure settings. Aggressive and socially disruptive behaviours do indeed occur in mental health settings (NICE 2015). Forensic patients are more likely to self-harm than the general population and approximately $30 \%$ of all offenders have committed some form of self-harm during their incarceration (Jeglic et al. 2005). Psychosis, especially when comorbid with substance misuse, has been associated with violence and violent offending (Fazel et al. 2009). Past history of violence, psychopathy, individual psychopathology, situational triggers and the restrictiveness of secure environments have been identified as predictors of aggression (Hill et al. 1996). Forensic settings are therefore likely to observe high levels of aggression given the complex mental health needs of most patients and their (criminogenic) history of harmful behaviour.

Risk management shapes the provision of secure care. Foremost, patients are mapped into low, medium and high security hospitals due to their assessed riskiness 
(Kennedy 2002). A precondition for placement within secure care is that an individual has committed a criminal act or is considered to pose a significant risk to themselves or others (NHS England 2018). Indeed, s.4 of the National Health Service Act 2006 stipulates that for admission into high security care, patients must have "[...] dangerous, violent or criminal propensities" (s.4 National Health Service Act 2006). Risk thus provides the raison d'etre for the structure of the secure system and directs the placement of patients. The primacy of risk also can be seen in the legally mandated use of risk assessment instruments when approving leave, grounds access and food brought in by family visitors (High Security Directions 2013).

Patients participating in the interviews described risk management procedures, primarily enacted by security teams, as over-bearing or intense, and security as a force to be reckoned with. They highlighted a range of belongings or activities prohibited on risk grounds, including amongst other things, access to a book on karate. For instance:

P17 - You're not allowed to have perfume bottles, that has to be put in the sharps cupboard because of the risk of glass being broken and people cutting themselves erm, you're not allowed sprays, any aerosols, they have to be kept, as well, out of your room.

Participants spoke of risk management subsuming other aspects of care.

P 12 - There's no other word for it. Risk is priority in this place. Absolute priority. If there's a risk of this happening or a risk of that happening, you know everything's taken into account.

Not all patients felt this way: one patient felt that risk management measures were needed '[...] cos you don't, you don't want us lot running around the streets, do you?' (P4).

Thus, a preoccupation with risk is pervasive in this setting. The prediction and management of harms has been cited by some as a feature of late modern societies (Beck 1992). Social theorists have argued that new modalities of social control have emerged that aim to model riskiness and exclude risky groups (Feeley and Simon 1992). However, within forensic mental health no single method or instrument exists that accurately predicts harm; indeed, "[r]isk thinking tames chance, fate and uncertainty by a paradoxical move" (Rose 1998: 180). Accordingly, where the management of risk shapes the provision of care and patients' ability to selfdetermine, this opens the possibility of individuals being subject to inappropriate levels of restriction. Studies have historically demonstrated that a significant number of forensic patients have been placed at inappropriately high levels of security. For example, Harty et al. (2004) found that $40 \%$ of high security residents surveyed were suitable for transfer to conditions of lower security. 


\section{Discussion: Increasingly implementing forensic mental health via a human rights approach?}

This paper has argued with reference to empirical data and literature that defining characteristics of late modern social control are visible within forensic mental health services. There is evidence that patients experience an othering, describing a double stigma and reduced ability to reintegrate into society. Patients describe a punitiveness in care, seeing length of stay and coercive measures as especially punishing. Punitive attitudes were held by some members of staff. Risk assessment and management were widely acknowledged as core concepts in forensic care. Risk was described as having an omnipresence shaping daily activities, progression through pathways and the structure of the forensic system.

Being perceived or treated as a stigmatised 'other' has consequences on patients' potential to interact in local communities, develop a sense of belonging and navigate life in the community (Corrigan and Watson 2006). Being subject to punishment or punishing attitudes can disrupt efforts towards inner peace and pleasure as patients may struggle to actualize behaviours that are not met with punishment or that given their individual psychopathology may not be readily achievable for them. The implementation of risk-averse policies and practices can thwart patients' abilities to exercise agency by engaging in creative and meaningful work and play. There is room for reform.

The presence of these late modern social control characteristics therefore might impede the full realisation of strength- and recovery-based approaches. Contemplating penal reform in the context of increasingly punitive and growing criminal justice systems, Snacken (2015) offers a framework of macro-level mechanisms of change that need to move in tandem in order for prison reform to occur. Applying Snacken's (2015) model to forensic mental health services might deepen our understanding of macro-level mechanisms of change shaping the adoption of strength- and recoverybased approaches. Snacken proposes that the adoption of moderate penal policies is - in part - contingent on legitimately exercised power operating within this framework of interacting mechanisms.

Drawing on Bottoms and Tankebe (2012), Snacken (2015) restates their assertion that this legitimacy includes three forms: the constitutional legitimacy to govern, the continued way in which power is exercised, and the existence and maintenance of shared values between those in power and the governed. Immanuel Kant (Kant 1784) saw this dialogue between the governed and the government as part of the Enlightenment process, arguing that critical discussion and free thinking amongst the former would shape the 'principles' of the later. He argued that (when the government was equally adept at critical thinking) this process would ultimately promote the dignity of each person.

This third form of legitimacy (shared values) is important as it offers a platform from which the pursuit of moderate penal policy can advance. Snacken (2015) suggests that the values of human rights and dignity are so called core values held in common across peoples. Conversely, specific values, which can include the enactment of particular aspects of the criminal justice system are more relative. Different 
social groups may hold different beliefs on how to realise moderate penal policy but that by appealing to human rights and dignity as shared core values, legitimate policy can be pursued that brings together social groups that hold different specific values.

We propose that interventions undertaken within strength- and recovery-based approaches and measures characteristic of late modern social control described in this paper are competing specific values, both in operation to various degrees. Key core values upon which arguments furthering the adoption of strength- and recovery-based approaches could be made would need to be identified to bridge this impasse. Snacken (2015) proposes that human rights and dignity would be helpful core values in penal reform. This reasoning is applicable to the forensic context also; locating facets of strength- and recovery-based approaches within a human rights frame reflects the emphasis of these approaches towards fostering hope, control and living beyond illness (Drennan et al. 2014). Well-recognised rights in congruence with these aims are woven into international human rights instruments, offering a heuristic and substantive framework for advocates of these treatment approaches.

The European Convention on Human Rights and Fundamental Freedoms (ECHR; 1953) offers a comprehensive set of rights that are applicable to forensic patients across its 47 member states. The right to respect for private and family life, home and correspondence under Article 8 provides a robust substantive framework, developed by the jurisprudence of the European Court of Human Rights (ECtHR), from which arguments in favour of strength- and recovery-based approaches could be derived.

Council of Europe guidance on Article 8 ECHR (1953) operationalizes this right into several spheres, of which 'physical, psychological or moral integrity', 'privacy' and 'identity and autonomy' are three (Council of Europe 2019). These stipulate that the following rights are crucial for one's private life and are therefore protected unless prohibited under lawful and proportionate exceptions: a sexual life; the right to form and develop relationships with other human beings and the outside world; the right to effective access to information concerning one's own health; the right to legal capacity; and 'a sphere within which [individuals] can freely pursue the development and fulfilment of their personality', appearance, gender and ethnic identity (Council of Europe, 2019: 47).

Restrictions to some of these rights are permitted under the ECHR (1953) but only where any restriction is 'in accordance with national law and is necessary in a democratic society in the interests of national security, public safety or the economic well-being of the country, for the prevention of disorder or crime, for the protection of health or morals, or for the protection of the rights and freedoms of others' (excerpt taken from Article 8; restrictions are justified differently in different provisions but follow a similar content).

The substantive rights contained within Art. 8 ECHR (1953) mirror in many respects the key elements of strength- and recovery-based approaches. Any restrictions on these strength- and recovery-based principles can therefore be contested within a cogent human rights framework. Where justifications for these restrictions are offered then individuals or systems proposing these restrictions need to navigate the conditions articulated by the ECtHR in its jurisprudence. These are often 
helpfully summarised and updated in guidance documents written by the Council of Europe (see for example: Council of Europe 2019). Healthcare providers must justify derivations from the ECHR within this framework. Training in the relevant provisions of the ECHR should be provided to all staff.

In summary, the full realisation of strength- and recovery-based principles is at odds with aspects of late modern social control visible within forensic mental health settings. Not wholly compatible, concepts of empowerment, individual autonomy, identity and connectedness abut with punitiveness, otherness and risk management. In attempting to dissolve disharmony between these, widely held core beliefs in the value of human rights might be drawn on. The European Convention on Human Rights (1953) offers a mature body of law and jurisprudence that may appeal to individuals favouring the implementation of strength- and recovery-based approaches. Grounding arguments in the language and heuristic framework of human rights can offer a set of core values that stimulate reform. Future research in this area should explore staff, stakeholder and patient perspectives on changes in modalities of care over recent years in light of developments in social control, and investigate their understanding of human rights in this context.

\section{Conclusion}

Forensic mental health exists and operates at a complex juncture bridging the criminal justice system and health services. This paper has empirically argued that characteristics of late modern social control, including punitiveness, otherness and the assessment and management of risk, are visible and performed within forensic services. These features of contemporary care shape the speed and manner in which strength- and recovery-based approaches to mental health care can be adopted. Therefore, we argue that advocates of these approaches should select human rights as a core value and springboard from which to implement such reform. The right to respect for private and family life, home and correspondence under Article 8 of the European Convention on Human Rights and Fundamental Freedoms offers a particularly promising, robust and well-defined framework for these future changes.

Acknowledgements This work was funded by the Economic and Social Research Council (ESRC) (Grant Number ES/J500100/1). We also thank Dr Nicola Wright for her comments and intellectual input on an earlier version of the manuscript.

Funding Open Access funding enabled and organized by Projekt DEAL.

\section{Declarations}

Conflict of interest The authors declare no conflicts of interest.

Open Access This article is licensed under a Creative Commons Attribution 4.0 International License, which permits use, sharing, adaptation, distribution and reproduction in any medium or format, as long as you give appropriate credit to the original author(s) and the source, provide a link to the Creative Commons licence, and indicate if changes were made. The images or other third party material in this article 
are included in the article's Creative Commons licence, unless indicated otherwise in a credit line to the material. If material is not included in the article's Creative Commons licence and your intended use is not permitted by statutory regulation or exceeds the permitted use, you will need to obtain permission directly from the copyright holder. To view a copy of this licence, visit http://creativecommons.org/licen ses/by/4.0/.

\section{References}

Anthony, William A. 1993. Recovery from Mental Illness: The Guiding Vision of the Mental Health Service System in the 1990s. Psychosocial Rehabilitation Journal 16 (4): 11. https://doi.org/10.1037/ h0095655.

Attride-Stirling, Jennifer. 2001. Thematic Networks: An Analytic Tool for Qualitative Research. Qualitative Research 1 (3): 385-405.

Barnao, Mary, and Tony Ward. 2015. Sailing Uncharted Seas without a Compass: A Review of Interventions in Forensic Mental Health. Aggression and Violent Behavior 22 (May): 77-86. https://doi.org/ 10.1016/j.avb.2015.04.009.

Barnao, Mary, Tony Ward, and Peter Robertson. 2016. The Good Lives Model: A New Paradigm for Forensic Mental Health. Psychiatry, Psychology and Law 23 (2): 288-301. https://doi.org/10.1080/ 13218719.2015.1054923.

Bauman, Zygmunt. 2000. Social Uses of Law and Order. In Criminology and Social Theory, 224, ed. David Garland and Richard Sparks. Oxford: Oxford University Press.

Beck, U. 1992. Risk Society: Towards a New Modernity. Geography 93: 122.

Bottoms, Anthony, and Justice Tankebe. 2012. Beyond Procedural Justice: A Dialogic Approach to Legitimacy in Criminal Justicespi. Journal of Criminal Law and Criminology 102 (1): 119-170.

Bouman, Yvonne H. A., Aart H. Schene, and Corine de Ruiter. 2009. Subjective Well-Being and Recidivism in Forensic Psychiatric Outpatients. International Journal of Forensic Mental Health 8 (4): 225-234. https://doi.org/10.1080/14999011003635647.

Corrigan, Patrick W., and Amy C. Watson. 2006. The Paradox of Self-Stigma and Mental Illness. Clinical Psychology: Science and Practice 9 (1): 35-53. https://doi.org/10.1093/clipsy.9.1.35.

Council of Europe. 2019. Guide on Article 8 of the European Convention on Human Rights Right to Respect for Private and Family. Updated on 31 August 2018. Available: https://rm.coe.int/guide-onarticle-8-of-the-european-convention-on-human-rights/16808e67cb. Accessed 7 July 2021.

Crisp, Arthur H., Michael G. Gelder, Susannah Rix, Howard I. Meltzer, and Olwen J. Rowlands. 2000. Stigmatisation of People with Mental Illnesses. British Journal of Psychiatry 177 (01): 4-7. https:// doi.org/10.1192/bjp.177.1.4.

Drennan, G., and J. Wooldridge. 2014. Making recovery a reality in forensic settings. Center for Mental Health \& Mental Health Network NHS Confederation. Implementing Recovery trough organisational Change, 1-28. Available at: https://imroc.org/wp-content/uploads/2016/09/10ImROC-brief ing-10-Making-Recovery-a-Reality-in-Forensic-Settings-final-for-web.pdf. Accessed 7 July 2021.

Fazel, Seena, Gautam Gulati, Louise Linsell, John R. Geddes, and Martin Grann. 2009. Schizophrenia and Violence: Systematic Review and Meta-Analysis. PLoS Medicine 6 (8): e1000120. https://doi. org/10.1371/journal.pmed.1000120.

Feeley, M.M., and J. Simon. 1992. The New Penology: Notes on the Emerging Strategy of Corrections and Its Implications. Criminology. https://doi.org/10.1111/j.1745-9125.1992.tb01112.x/full.

Garland, David. 2001. The Culture of Control Crime and Social Order in Contemporary Society. London: Oxford University Press.

Garland, David, and Richard Sparks. 2000. Criminology and Social Theory. Oxford: Oxford University Press.

Goshe, Sonya. 2017. The Lurking Punitive Threat: The Philosophy of Necessity and Challenges for Reform. Theoretical Criminology. https://doi.org/10.1177/1362480617719450.

Hallsworth, S. 2000. Rethinking the Punitive Turn: Economies of Excess and the Criminology of the Other. Punishment \& Society 2 (2): 145-160. https://doi.org/10.1177/14624740022227926.

Harty, Mari Anne, Jenny Shaw, Stuart D. Thomas, Mairead Dolan, Lisa Davies, Graham Thornicroft, Julie Carlisle, et al. 2004. The Security, Clinical and Social Needs of Patients in High Security 
Psychiatric Hospitals in England. Journal of Forensic Psychiatry and Psychology 15 (2): 208-221. https://doi.org/10.1080/14789940410001703967.

Hill, Christie D., Richard Rogers, and Michael E. Bickford. 1996. Maxi-Mum Security Forensic Psychiatric Hospital. Journal of Forensic Sciences, JFSCA. 41: 1112.

Hollway, Wendy, and Tony Jefferson. 1997. The Risk Society in an Age of Anxiety: Situating Fear of Crime. British Journal of Sociology 48 (2): 255-266.

Holmes, D., and S.J. Murray. 2011. Civilizing the 'Barbarian': A Critical Analysis of Behaviour Modification Programmes in Forensic Psychiatry Settings. Journal of Nursing Management 19 (3): 293301. https://doi.org/10.1111/j.1365-2834.2011.01207.x.

Horberg, U., R. Sjogren, and K. Dahlberg. 2012. To Be Strategically Struggling against Resignation: The Lived Experience of Being Cared for in Forensic Psychiatric Care. Issues in Mental Health Nursing 33 (11): 743-751. https://doi.org/10.3109/01612840.2012.704623.

Jacobson, Nora, and Dianne Greenley. 2001. What Is Recovery? A Conceptual Model and Explication. Psychiatric Services 52 (4): 482-485. https://doi.org/10.1176/appi.ps.52.4.482.

Jeglic, Elizabeth L., Holly A. Vanderhoff, and Peter J. Donovick. 2005. The Function of Self-Harm Behavior in a Forensic Population. International Journal of Offender Therapy and Comparative Criminology 49 (2): 131-142. https://doi.org/10.1177/0306624X04271130.

Jewkes, Yvonne, Melanie Jordan, Serena Wright, and Gillian Bendelow. 2019. Designing 'Healthy' Prisons for Women: Incorporating Trauma-Informed Care and Practice (TICP) into Prison Planning and Design. International Journal of Environmental Research and Public Health 16 (20): 3818. https:// doi.org/10.3390/ijerph16203818.

Kant, Immanuel. 1784. An Answer to the Question: What Is Enlightenment? [Translated by Ted Humphrey, 1992]. Berlinische Monatsschrift A. A. VIII: 33-42.

Kennedy, Harry G. 2002. Therapeutic Uses of Security: Mapping Forensic Mental Health Services by Stratifying Risk. Advances in Psychiatric Treatment 8 (6): 433-443. https://doi.org/10.1192/apt.8. 6.433 .

Koch, Insa. 2017. Moving beyond Punitivism: Punishment, State Failure and Democracy at the Margins. Punishment \& Society 19 (2): 203-220. https://doi.org/10.1177/1462474516664506.

Kvale, Steinar. 2008. Doing Interviews. Sage.

Leamy, M., V. Bird, C. Le Boutillier, J. Williams, and M. Slade. 2011. Conceptual framework for personal recovery in mental health: systematic review and narrative synthesis. The British Journal of Psychiatry 199 (6): 445-452.

Lewis, Sam, Adam Crawford, and Peter Traynor. 2016. Nipping Crime in the Bud? The Use of Antisocial Behaviour Interventions with Young People in England and Wales. British Journal of Criminology. https://doi.org/10.1093/bjc/azw072.

Lynn, P. J. 2016. Principles of Sampling. In Research Methods for Postgraduates, ed. Greenfield, Tony and Greener, Sue, Third Edition, 244-254. Wiley. ISBN 9781118341469.

Markham, Sarah. 2018. Red-Teaming the Panopticon* (Mobilising Adaptive Change in Secure and Forensic Settings). Edited by Ansari Addison Askola, Atanasov, Bagaric, Barker, Bernstein, Buckingham, Constantinou, Corrigan, Currie, Davison, de Vries Robbe, Dike-Ugwu, Doyle, Drennan, Druzin, Eastman, Faulkner, Fazel, Feldman, Fitzgibbon, Garcia-Retamero, Giluk, Gough, Gowing, Gray, Gree. Journal of Forensic Psychiatry 29 (1): 16-36. https://doi.org/10.1080/14789949.2017. 1335761.

Mezey, G., M. Kavuma, P. Turton, A. Demetriou, and C. Wright. 2010. Perceptions, Experiences and Meanings of Recovery in Forensic Psychiatric Patients. Journal of Forensic Psychiatry \& Psychology 21 (5): 683-696. https://doi.org/10.1080/14789949.2010.489953.

Mezey, G., H. Youngman, I. Kretzschmar, and S. White. 2016. Stigma and Discrimination in Mentally Disordered Offender Patients - a Comparison with a Non-Forensic Population. Journal of Forensic Psychiatry and Psychology 27 (4): 517-529. https://doi.org/10.1080/14789949.2016.1172658.

Middleton, Hugh, and Melanie Jordan. 2017. Mental Health Uncertainty and Inevitability: Rejuvenating the Relationship between Social Science and Psychiatry. Mental Health Uncertainty and Inevitability: Rejuvenating the Relationship between Social Science and Psychiatry. Springer International Publishing. https://doi.org/10.1007/978-3-319-43970-9.

Morley, Sharon, and Paul Taylor. 2016. 'Cashing In' on Curiosity and Spectacle: The Forensic Patient and News Media. Journal of Forensic Psychiatry and Psychology 27 (5): 705-721. https://doi.org/ 10.1080/14789949.2016.1187760.

Murphy, Paula, Lucy Potter, John Tully, Dave Hearn, Thomas Fahy, and Paul McCrone. 2017. A Cost Comparison Study of Using Global Positioning System Technology (Electronic Monitoring) in a 
Medium Secure Forensic Psychiatric Service. Journal of Forensic Psychiatry and Psychology 28 (1): 57-69. https://doi.org/10.1080/14789949.2016.1261172.

NHS England. 2018. Service Specification: Low Secure Mental Health Services (Adult). Available at: https://www.england.nhs.uk/publication/service-specification-low-secure-mental-health-servicesadult/. Accessed 7 July 2021.

NICE. 2015. Violence and aggression: short-term management in mental health, health and community settings. NICE guideline [NG10]. Available at: https://www.nice.org.uk/guidance/ng10. Accessed 7 July 2021

Office for National Statistics. 2019. Crime in England and Wales: Year Ending March 2019. Available at: https://www.ons.gov.uk/peoplepopulationandcommunity/crimeandjustice/bulletins/crimeinenglanda ndwales/yearendingmarch2019. Accessed 7 July 2021.

Parrott, F. 2005. 'It's Not Forever': The Material Culture of Hope. Journal of Material Culture 10 (3): 245-262. https://doi.org/10.1177/1359183505057151.

Prison Reform Trust. 2019. Prison: The Facts. Bromley Briefings Summer 2019. Available at: http:// www.prisonreformtrust.org.uk/Portals/0/Documents/Bromley\%20Briefings/Prison \%20the\%20fac ts\%20Summer\%202019.pdf. Accessed 7 July 2021.

Quinn, Chris, and Brenda Happell. 2016. Supporting the Sexual Intimacy Needs of Patients in a Longer Stay Inpatient Forensic Setting. Perspectives in Psychiatric Care 52 (4): 239-247. https://doi.org/10. 1111/ppc.12123.

Rees, G. 2015. Contentious Roommates? Spatial constructions of the therapeutic-evidential spectrum inmedicolegal work. In The Clinic and the Court: Law, Medicine and Anthropology, ed I. Harper, T. Kelly, and A. Khanna, 141-160 (Cambridge Studies in Law and Society). Cambridge: Cambridge University Press. https://doi.org/10.1017/CBO9781139923286.007.

Reiner, Robert. 2012. Beyond Risk: A Lament for Social Democratic Criminology. In The Politics of Crime Control: Essays in Honour of David Downes. New York: Wiley.

Rose, N. 2000. Government and Control. British Journal of Criminology 40 (2): 321-339. https://doi.org/ 10.1093/bjc/40.2.321.

Rose, Nikolas. 1998. Governing Risky Individuals: The Role of Psychiatry in New Regimes of Control. Psychiatry, Psychology and Law 5 (2): 177-195. https://doi.org/10.1080/13218719809524933.

Ruane, J., and M. Hayter. 2008. Nurses' Attitudes towards Sexual Relationships between Patients in High Security Psychiatric Hospitals in England: An Exploratory Qualitative Study. International Journal of Nursing Studies 45 (12): 1731-1741. https://doi.org/10.1016/j.ijnurstu.2008.06.003.

Rutherford, A. 2006. Dangerous people: beginnings of a New Labour proposal. In The Politics of Crime Control: Essays in Honour of David Downes, ed. Newburn, Tim and Rock, Paul, 51-89. (Clarendon Studies in Criminology) Oxford, UK: Oxford University Press.

Silverman, David. 2015. Interpreting Qualitative Data. Sage.

Simon, Jonathan. 1998. Managing the Monstrous: Sex Offenders and the New Penology. Psychology, Public Policy, and Law 4 (1-2): 452-467. https://doi.org/10.1037/1076-8971.4.1-2.452.

Simpson, Alexander I.F.., and Stephanie R. Penney. 2018. Recovery and Forensic Care: Recent Advances and Future Directions. Criminal Behaviour and Mental Health, September. https://doi.org/10.1002/ cbm. 2090.

Simpson, Alexander I F., and Stephanie R. Penney. 2011. The Recovery Paradigm in Forensic Mental Health Services. Criminal Behaviour and Mental Health 21 (5): 299-306. https://doi.org/10.1002/ cbm.823.

Snacken, Sonja. 2015. Punishment, Legitimate Policies and Values: Penal Moderation, Dignity and Human Rights. Punishment \& Society 17 (3): 397-423.

Tomlin, Jack, Peter Bartlett, and Birgit Völlm. 2018. Experiences of Restrictiveness in Forensic Psychiatric Care: Systematic Review and Concept Analysis. International Journal of Law and Psychiatry 57: 31-41. https://doi.org/10.1016/j.ijlp.2017.12.006.

Tomlin, Jack, Vincent Egan, Peter Bartlett, and Birgit Völlm. 2020. What Do Patients Find Restrictive About Forensic Mental Health Services? A Qualitative Study. International Journal of Forensic Mental Health 19 (1): 44-56. https://doi.org/10.1080/14999013.2019.1623955.

Warburton, Katherine D. 2016. A New Standard of Care for Forensic Mental Health Treatment: Prioritizing Forensic Intervention. Violence in Psychiatry., 252-257. https://doi.org/10.1017/S109285291 5000140 .

Ward, Tony, and Mark Brown. 2004. The Good Lives Model and Conceptual Issues in Offender Rehabilitation. Psychology, Crime \& Law 10 (3): 243-257. https://doi.org/10.1080/106831604100016 62744. 
Publisher's Note Springer Nature remains neutral with regard to jurisdictional claims in published maps and institutional affiliations.

Jack Tomlin is a post-doctoral research fellow at the Department for Forensic Psychiatry at Rostock University Medical Center, Germany. His background is in criminology, law and human rights. He completed his Ph.D. in 2019 exploring forensic patient experiences of care with a mixed methods research design at the University of Nottingham, UK. There he also held teaching and research posts. He is on the Editorial Boards of Frontiers in Psychiatry, Forensic Psychiatry specialty section and the International Journal of Forensic Mental Health, and has a developing body of international literature. He supervises undergraduate and postgraduate students.

Melanie Jordan undertakes undergraduate and postgraduate teaching as well as $\mathrm{Ph} . \mathrm{D}$. supervision plus personal and collaborative research and publication -in the fields of criminology and sociology. Melanie also works with governmental and non-governmental bodies and charities as an advisor on elements of prisons, survivor services, public protection policing, secure sites, care settings, mental health, therapeutic environments, etc. Melanie has a Ph.D. in Prison Mental Health, a MA in Research Methods, and a B.A. in Social Policy. Dr. Mel Jordan spent the Michaelmas Term of 2017 at the University of Oxford, Centre for Criminology, with Prof. Mary Bosworth et al., as an Academic Visitor-while on Study Leave from the University of Nottingham. Dr. Melanie Jordan is an Associate Professor in Criminology at the Faculty of Social Sciences at the University of Nottingham, U.K. Melanie also runs a research group critically exploring imprisonment, Prisons 4 Good, which also includes a charitable music organisation Bars Bridging Bars. 